\title{
Клиничен случай на гломусен тумор в напреднал стадий
}

\author{
Аврамов $\mathrm{T}^{1}$., Ал. Карапанчев ${ }^{1}$, \\ О. Стоянов ${ }^{1}$, А. Манолова ${ }^{2}$ \\ 'УНГ-клиника, УМБАЛ „Ц. Йоанна-ИСУЛ“ - София \\ ${ }^{2}$ Национален центьр по обществено здраве и анализи - София
}

\section{Резюме:}

Въведение: Параганглиомите са рядко срещани тумори, които могат да се развият на различни места в човешкото тяло $-85 \%$ в областта на корема, $12 \%$ в областта на гърдите и $3 \%$ в областта на главата и шията. Тези в областта на главата и шията в зависимост от местоположението си могат да се подразделят на: каротидни (бифуркацията на артерия каротис), гломус тимпаникус (glomus tympanicum), гломус югуларе (glomus jugulare) и вагусова параганглиома. Те съставляват $0,6 \%$ от неоплазмите на главата и шията.

Материал и метод: Клиничен случай на 65-годишна пациентка Л. К. В., постьпила за диагностично уточняване и лечение в УНГ-клиника при УМБАЛ „Ц. Йоанна-ИСУЛ“ по повод дрезгав глас и прокървяване от дясното ухо. Поради големината на образуванието във външния слухов канал беше взета само биопсия и след направена компютърна томография с контраст бяха обсъдени възможностите за лечение на клиникорадиологична среща.

Резултати: Поради много напредналия стадий на заболяването на пациентката след обсъждане с неврохирург, радиолог и рентгенолог беше взето решение за провеждане на лъчетерапия, поради рисковете, които крие хирургична намеса дори и след селективна емболизация.

Заключение: Хирургичното лечение е метод на избор при пациенти с гломусни тумори в ранен стадий. Прилагането на селективна емболизация предоперативно или като самостоятелен лечебен метод има ефект при ранните стадии. При напреднала възраст на пациента и напреднал стадий на образуванието е подходящо единствено провеждане на лъчетерапия.

Ключови думи: параганглиом, гломус югуларе, неоплазми на главата и шията, селективна емболизация, лъчетерапия

\section{Въведение}

Въпреки че съдовите тумори на средното ухо са били описани още в началото на двадесети век, произходът на гломус югуларе не е бил изяснен до 1941 година, когато Stacey Guild (1) го открива и описва. През 1945 година Rosenwasser (1) съобщава за отстранен тумор от средното ухо, който хистологично прилича на гломус югуларе. След тази година този доброкачествен тумор се оказва най-често възникващият в средното ухо. През 1950 година Milligan $(2,3)$ му дава името хемодектом, подчертавайки, че произходът на тумора е от хеморецепторните клетки. През 1974 година Glenner и Grimley (2, $3)$, базирайки се на анатомичните и физиологичните му особености му дават името параганглиом. Смята ce, че честотата му е един на 300000 души от населението. Параганглиомът е вид тумор, който възниква от периферната нервна система, която е разделена на симпатиковата и парасимпатикова. Един от всеки четири диагностицирани параганглиоми е наследен като част от синдром на фамилна параганглиома, множествена ендокринна неоплазия тип 2, синдром на фон Хипел-Линдау или неврофиброматоза (3). Дефекти в гени, като подразделения В (SDHB), C (SDHC) и D (SDHD) на сукцинат дехидрогеназата e известно, че са свързани със синдром на фамилната 


\section{Abstract:}

Introduction: Paragangliomas are rare tumors which may occur at various locations in the human body, $85 \%$ of the abdomen, $12 \%$ in the area of the breast and $3 \%$ of the head and neck. Those in the field of head and neck depending on your location can be divided into: carotid (bifurcation of the carotid artery), timpanic glomus (glomus tympanicum), jugular glomus (glomus jugulare) and vagal paraganglioma. They make up $0.6 \%$ of the neoplasms of the head and neck. Material and methods: Clinical case of 65 year-old patient L.K.V. submitted on diagnostics and treatment in the ENT Clinic at the University Hospital „Tz. Joanna-ISUL „on the occasion of hoarseness and bleeding from the right ear. Due to the size of the entity in the external auditory canal, was taken only biopsy and after CT scan with contrast were discussed treatment options of clinikal meeting.

Results: Due to the very advanced stage of the disease the patient after discussion with the neurosurgeon and radiologist was decided to conduct radiation therapy because of the risks inherent in surgery after selective embolization.

Conclusion: Surgery is the treatment of choice in patients with glomusni tumors at an early stage. The application of selective preoperative embolization or as alone treatment method effective in early stage. In old age of the patient and advanced tumors is only suitable conducting radiotherapy.

List alphabetically abbreviations:

$\mathrm{CN}$ - cranial nerves, CT-

Key words: paraganglioma, glomus jugulare, neoplasms of the head and neck, selective embolization, radiation параганглиома. Наследените форми на параганглиома могат да бъдат свързани с:

$\checkmark$ млада възраст при диагностицирането

$\checkmark$ фамилната анамнеза на надбъбречната жлеза или бъбречни тумори

$\checkmark$ фамилната анамнеза на феохромоцитом

$\checkmark$ внезапна необяснима смърт в ранна възраст

Гломус югуларе е малка $(0,5$ х 0,5 х 0,25 мм) жлезиста структура (4), сходна с каротидното телце. Тя се състои от гнезда нехроматофинни клетки, разполагащи се на гроздове около тънкостенни съдови канали. Обикновено има няколко от тях във всяка темпорална кост, като може да се намерят също и по купола на югуларния булбус (glomus jugulare), по протежение на нерва на Jacobson (glomus tympanicus), плексус тимпаникус или нерва на Arnold. Tе обикновено произлизат от хипотимпанума, където нервус тимпаникус навлиза в тъпанчевата кухина или от адвентицията на булбус вене югуларис. Описано е и възникването му върху промоториума. Наблюдаваното съотношение мъже/жени е 1:5. Туморите са изключително добре кръвоснабдени, състоящи се от съдови синуси, кръвоснабдявани от артерия фарингеа асценденс. В преобладаващата си част са доброкачествени и с бавен растеж. Въпреки че при всеки случай скоростта на нарастване е различна, обикновено изминават двадесет години от появяването до диагностицирането им. Тези тумори много рядко метастазират, но имат деструктивен характер поради инвазията им в околните структури. В много редки случаи туморьт може да секретира катехоламини, което клинично се проявява с хипертония, главоболие, сърцебиене и тахикардия. Когато се развиват инфратемпорално в шийния отдел на nervus vagus, говорим за glomus vagale, а в областта на каротидната бифуркация за glomus caroticus.

Най-ранният симптом на заболяването е шумът, който е най-често пулсиращ. След това настьпва слухова загуба и тя е в пряка зависимост от нарастването на тумора. Когато се наруши целостта на тъпанчевата мембрана, наблюдаваме прокървяване и секреция от ухото, дължаща се на вторична инфекция. С напредване на процеса често се наблюдава парализа на нервус фациалис, а при инвазия в областта на форамен югуларе се засягат IX, X, XI и XII черепномозъчни нерви. Болка като оплакване обаче се среща много рядко.

Диагностицирането на тумора не винаги е лесно. При прегледа в ранните стадии се открива червени- 
каво издуване зад тъпанчевата мембрана, което при голямо увеличение на микроскопа може да се види, че пулсира. Ако тъпанчевата мембрана е матова, а туморьт е мальк, находката може да се обърка със симптома на Schwartze при отосклероза. Когато туморът започне да нараства, той причинява изпъкване на долната част на тъпанчевата мембрана. Когато наруши накрая целостта ѝ, във външния слухов канал се визуализира полипоидно тъмночервено гладко туморно образувание, лесно кървящо, а понякога и обилно при манипулация. При повишаване на налягането във външния слухов канал с отоскопа по Siegle туморът увеличава пулсациите си и избледнява. В ранните стадии рентгеновото изследване има малка стойност, но с нарастване на тумора вече показва костната деструкция, която той причинява. Все по-широка употреба намира при диагностициране на тумора препаратьт metaiodobenzylguanidine (MIBG). Той се използва за откриване и диагностика на някои тумори в тялото като феохромоцитом или невробластом, които са тумори на нервната тъкан. Когато MIBG се комбинира с радиоактивен йод (маркер), това ни дава възможност за идентифициране дали процесьт е първичен или метастатичен.

При напреднали случаи ангиографията на външната сънна артерия е много полезна за очертаване степента на разпространение на тумора. Поставянето на диагнозата се извършва с биопсия. Когато тъпанчевата мембрана е интактна (ранен стадий), първоначално се извършва тимпанотомия и при възможност се отстранява целият тумор.

Alford и Guilford (5) въвеждат в клиничната практика стадиране на гломусните тумори, включващо пет стадия:

- Стадий 0. При този стадий се появяват найранните симптоми на гломусния тумор. Оплакванията на пациента се изразяват в слухова загуба и/или пулсиращ шум. Слухът може да е нормален или загубата да е от проводен тип. Тъпанчевата мембрана е интактна, но помътнена. На компютърната томография (KT) не се установяват патологични промени.

- Стадий I. Към гореспоменатите симптоми се прибавя и секреция от външния слухов канал, дължаща се на нарушаване целостта на тъпанчевата мембрана от туморния про- цес. На КТ се вижда засенчване в областта на средното ухо, но ерозия на костта не се наблюдава.

- Стадий II. Появява се парализа на лицевия нерв и слуховата загуба вече става невросензорна. На КТ не се вижда костна ерозия, а само в редки случаи разширяване на foramen jugulare.

- Стадий III. Обхващането на foramen jugulare причинява парализата на IX, X, XI и XII ЧМН. На КТ се вижда ерозия на скалистата част (pars petrosa ossis temporalis) на слепоочната кост и разширяване на foramen jugulare.

- Стадий IV. Започва вьтречерепна експанзия и се установява едем на папилите. Широкото обхващане на скалистата част на темпоралната кост се изразява и в парализата на III, IV, V и VI ЧМН.

Друга често използвана класификация е тази на Glasscock-Jackson. Класификацията разглежда четири етапа на развитие на тумора:

А - тумор, ограничен в кухината на средното ухо (glomus tympanicum).

В - тумор, ограничен в тимпаномастоидната зона, без вътрелабиринтно разпространение.

C - тумор с вътрелабиринтно разпространение в слепоочната кост и разпространение към апекса на скалистата част на темпоралната кост.

- $C 1$ - тумор с ограничено участие на вертикалната част на каротидния канал.

- $C 2$ - тумор, нахлуващ във вертикалната част на каротидния канал.

- $C 3$ - туморна инвазия в хоризонталната част на каротидния канал.

- D - тумор с вътречерепно разпространение.

- D1 - тумор с вътречерепно разпространение по-малко от 2 см в диаметьр.

- D2 - тумор с вътречерепно разпространение по-голям от 2 см в диаметър.

\section{Материал и метод}

Представяме клиничен случай на 65-годишна пациентка Л. К. В., постъпила за диагностично уточняване и лечение в УНГ клиника при УМБАЛ „Ц. Йоанна-ИСУЛ“ по повод дрезгав глас, глухота на дясното ухо и прокървяване от същото. Слухът прогресивно намалявал през 
последните петнадесет години, като бил придружен от силен шум в същото ухо и периодична секреция. Преди година и половина гласът на пациентката се променил, станал дисфоничен, с повишена гласова уморяемост. От проведените изследвания тогава се установява парализа на дясна истинска гласна връзка. Проведените рентгенография на бял дроб и сърце и рентгенография на хипофаринкс и хранопровод с контраст били негативни и поради това се приело, че се касае за идиопатична парализа на гласната връзка. Проведена била гласова рехабилитация и се наблюдавало осезаемо подобрение на гласа.

През месец ноември пациентката беше изпратена за провеждане на гласова рехабилитация и при прегледа сподели, че от 15 дни дясното ѝ ухо прокървява. При извършената отоскопия се видя Ту образувание с червеникава гладка повърхност, изпълваща почти две трети от външния слухов канал и оскъдно количество слузестогноен ексудат около него. Тъпанчевата мембрана не можа да се визуализира. При аспирацията образуванието обилно прокървя, което наложи поставянето на пльтна марлена тампонада в канала. От проведените предна и задна риноскопия не се установиха патологични промени. Находката при мезофарингоскопия леко хиперемирана мезофарингеална лигавица, увула, меко небце. При индиректна ларингоскопия - парализирана дясна истинска гласна връзка, разположена в интермедиерно положение, лява истинска гласна връзка подвижна, хиперфонира.

От аудиограмата - глухота в дясно, невросензорна загуба на слуха в ляво.

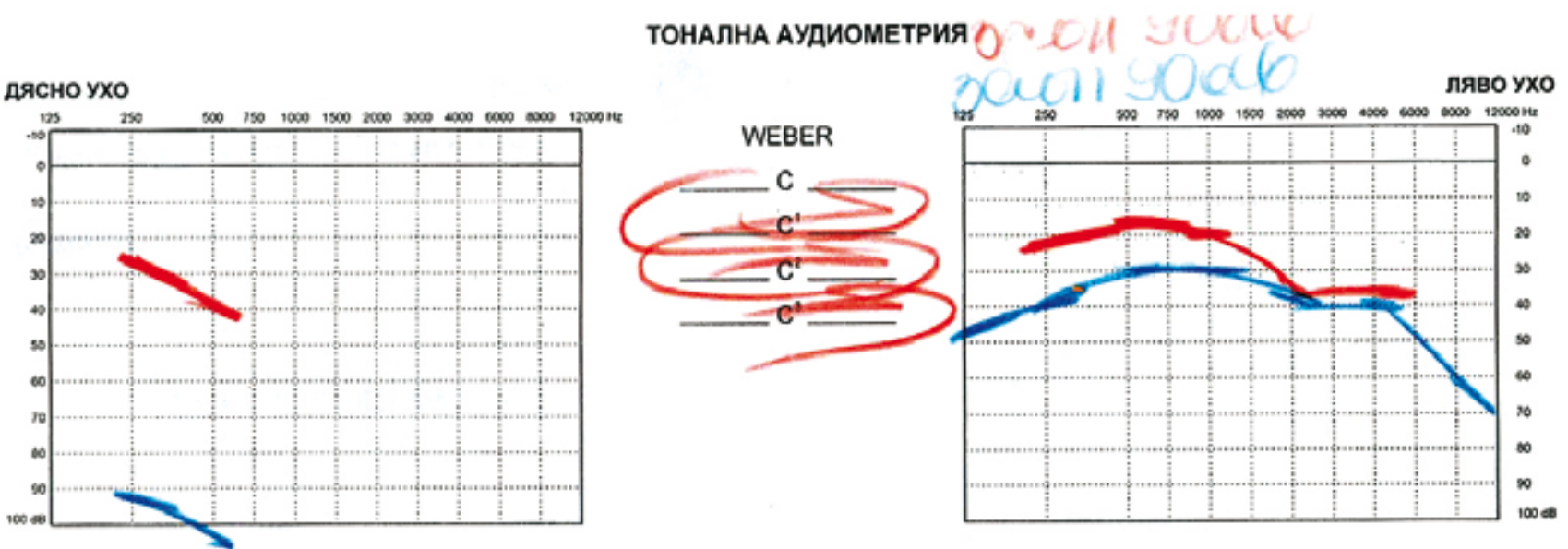

Фиг. 1. Тонална аудиометрия

Проведените параклинични изследвания бяха в норма.

Придружаващи заболявания - хипертонична болест.

От отоневрологичното изследване:

Вестибуларни симптоми: нистагъм - спонтанен хоризонтален асоцииран бърз дребен II степен наляво.

Координационни проби изпълнява добре.

Статокинетични проби: Бабински Вайл - атаксична походка.

Други проби - Зенгер отрицателен /-/.

От проведената КТ с контрастна материя:

Мекотъканна формация в десния понтоцеребеларен ьгъл с неправилна форма и размери
25/32 мм, навлизаща в дясната малкомозъчна хемисфера и лизираща костните структури на дясната пирамида. Находката отговаря на десностранен югуларен тумор.

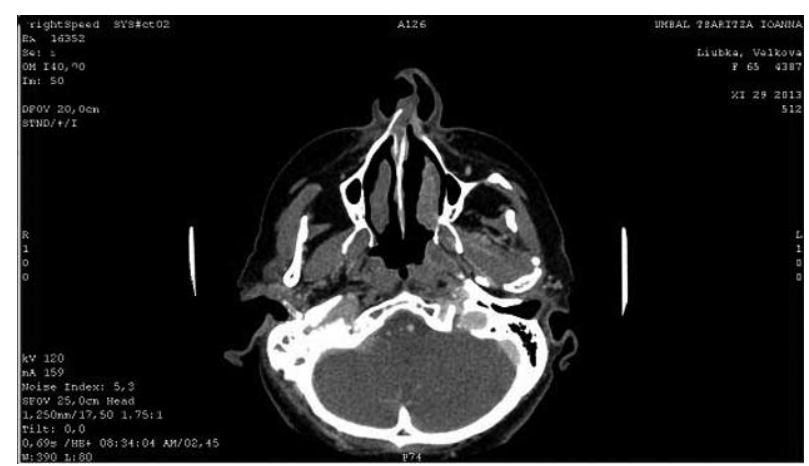

Фиг. 2. КТ на глава с контраст 


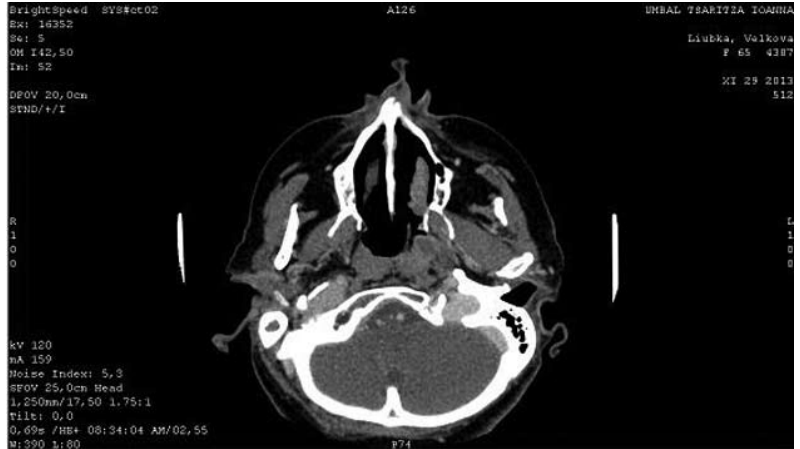

Фиг. 3. КТ на глава с контраст

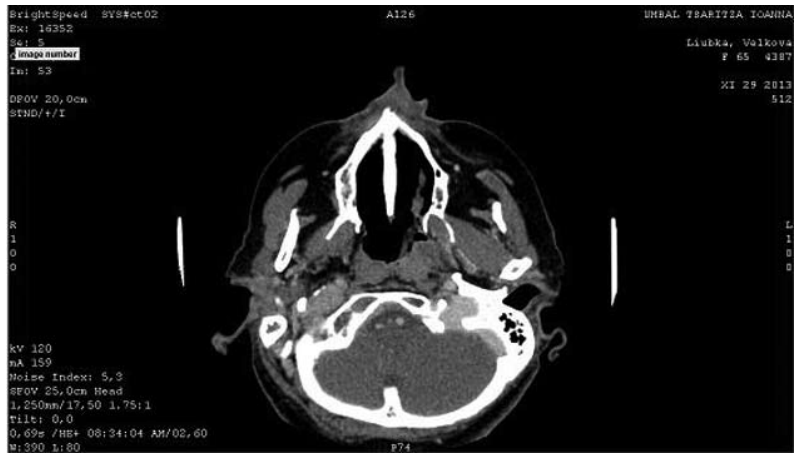

Фиг. 4. КТ на глава с контраст

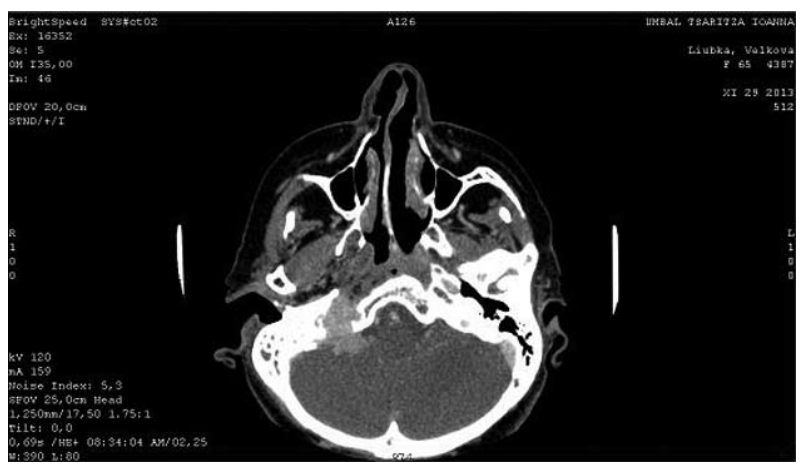

Фиг. 5. КТ на глава с контраст

\section{Резултати}

Поради големината на образуванието във външния слухов канал беше взета само биопсия и след направената компютьрна томография с контраст бяха обсъдени възможностите за лечение на клиникорадиологична среща. Поради много напредналия стадий, тумор с вътречерепно разпространение по-голямо от 2 см в диаметьр (стадий D2 по Glasscock-Jackson) на заболяването на пациентката, се взе решение след обсъждане с неврохирург, радиолог и рентгенолог за провеждане на льчетерапия, поради рисковете, които крие хирургичната намеса дори след провеждането на суперселективна емболизация.

\section{Заключение}

Лечението при всеки пациент е индивидуално и зависи от стадия. В ранните стадии след радикално отстраняване може да се постигне пълно излекуване, докато при много напредналите случаи то е само палиативно. Прилагането на суперселективна емболизация предоперативно или като самостоятелен лечебен метод също има ефект при ранните стадии.

По класификацията на Alford и Guilford при стадий I, когато туморът обхваща единствено средното ухо, той може да се отстрани тотално чрез тимпанотомия. Отстраняването трябва да започне от хипотимпанума. При разпространение на процеса в атика или мастоидния израстък (стадий I или II) е необходимо извършване на мастоидектомия. При разпространен процес кървенето от него може да бъде животозастрашаващо и се налага лигиране на артерия фарингеа асценденс. При стадий III, когато процесьт обхваща форамен югуларе, хирургичната интервенция е възможна, но много трудна. Успешна интервенция може да се извърши при условие, че преди това са лигирани латералният синус и вена югуларис. Задължително е следоперативно да се извърши и лъчелечение.

Лъчетерапията е често използван метод на избор в случаите, когато не може да се отстрани туморният процес радикално (стадий III и IV). При напреднала възраст на пациента и напреднал стадий на образуванието е подходящо единствено провеждане на лъчетерапия.

Трябва да се отбележи, че тези тумори са в известна степен лъчерезистентни. По тази причина се постига само известно намаление на размера на тумора $(6,7)$.

В клиничната практика навлиза все по-широко и гама-ножьт. Това е неинвазивна неврохирургична процедура, при която се използват мощни дози насочена радиация за лечение на тумори на мозъчната тькан, съхранявайки околните тъкани (7).

Напоследък при лечение при напреднали стадии намира място приложението на препарата октреотид (octreotide) с цел забавяне растежа на туморите (7).

Независимо от вида на провежданото лечение при тези пациенти е наложително дългогодишно проследяване. 


\section{Книгопис:}

1. Alford BR, Guilford FR., Tumors of the glomus jugulare. Laryngoscope, 1962; 72; 763

2. Павлов В., А. Караджова, Б. Сеизова, Гломусни тумори в областта на главата и шията-представяне на случай, Ото-риноларингология, Година IX, 2005, 1, 54- 5.

3. Austin D., Benign tumors of middle ear. Otorhinolaryngology Head and Neck Surgery, 1996: 985-987.

4. Koenigsberg R., Glomus Tumor (Head and Neck), eMedicine: 2002
5. Semaan MT, Megerian CA. Current assessment and management of glomus tumors. Curr Opin Otolaryngol Head Neck Surg. 2008;16(5):420-6

6. Gottfried ON, Liu JK, Couldwell WT. Comparison of radiosurgery and conventional surgery for the treatment of glomus jugulare tumors. Neurosurg Focus. 2004, 15;17(2)

7. Krych AJ, Foote RL, Brown PD, et al; Long-term results of irradiation for paraganglioma. Int $\mathrm{J}$ Radiat Oncol Biol Phys. 2006;65(4):1063-6.

\section{Автор за кореспонценция:}

Д-р Тома Аврамов

УНГ-клиника, УМБАЛ „Ц. Йоанна-ИСУЛ“,

ул. „Бяло море “№ 8,

София

toma_avramov@abv.bg

tel.+35929432563 